Journal of Engineering and Applied Sciences 7 (2): 134-142, 2012

ISSN: 1816-949X

(C) Medwell Journals, 2012

\title{
Prediction of Air Temperature Using Artificial Intelligent Methods
}

\author{
Mohammad Ali Ghorbani, Honeyeh Kazemi, Davod Farsadizadeh and Peyman Yousefi \\ Department of Water Engineering, Faculty of Civil Engineering, Tabriz University, Tabriz, Iran
}

\begin{abstract}
Estimation of air temperature is one of the important problems in agricultural planning also in water resources management which can be done by using different empirical, semi-empirical and intelligent methods. In the present study, Adaptive Neuro Fuzzy Inference System, artificial neural networks and genetic programming are used to estimate maximum, minimum and mean air temperature values in the synoptic station of Tabriz city, Northwest Iran. Considering the statistical indices, in spite of some very slight differences in the accuracy and error of the models, all three models are able to accurately estimate the minimum, mean and maximum air temperature. Also, explicit solutions that show the relation between input and output variables are presented based on genetic programming. This adds to the superiority of genetic programming over the other two models.
\end{abstract}

Key words: Adaptive Neuro Fuzzy Inference System, air temperature, artificial neural networks, genetic programming, Tabriz, Iran

\section{INTRODUCTION}

Prediction of air temperature value is very important in water resources management, agriculture and totally in many daily problems. Damage to plants and animals caused by extreme temperature is a serious concern for agricultural producers. Air temperature is also one of the input variables of land assessment, ecological and hydrological models (Abde-Al and El-Hadidi, 1994). Different empirical or semi-empirical models, time series analysis and intelligent methods such as artificial neural networks, fuzzy logic, neuro fuzzy and genetic programming are used for the estimation of air temperature. Several attempts have been made to obtain semi-empirical models such as the Brunt (1941) Model which is one of the most applicable models in prediction of air temperature and is based on the analytical solution of the energy balance equation. In recent years, new intelligent methods have largely been applied in all scientific and engineering fields (Elizondo et al., 1994; Panigrahi and Francl, 1997). The application of Artificial Neural Network (ANN) Models is quickly increasing due to easy application and high accuracy of these models to approximate complex non-linear mathematical equations (Paruelo and Tomasel, 1997; Patterson, 1996).

Genetic Programming (GP) is among heuristic algorithms all of which are based on Darwin's evolution theory. The mentioned algorithms define a target function in the shape of qualitative standards and then make use of the mentioned function to measure and compare different solution methods in a step by step process of data source correction and finally present the appropriate solution method. Also, Adaptive Neuro Fuzzy Inference System (ANFIS) has been used to analyze the non-linear phenomena and to estimate the relation between inputoutput in systems consisting of various parameters. ANNs have been used to classify and estimate the minimum air temperature values (Abde-Al and El-Hadidi, 1994; Robinson and Mort, 1997). Ustaoglu et al. (2008) used three different ANN Methods to forecast daily minimum, maximum and mean air temperature time series and found them quite reliable in the temperature estimation study. Dombayci and Golcu (2009) developed an ANN Model to predict daily mean ambient temperatures in Denizli, South-Western Turkey and found it a reliable model. Smith et al. (2009) explored the application of ANNs for the prediction of air temperature during the entire year based on near real-time data. The ANNs were able to provide predictions throughout the year. Real-time runoff forming (Khu et al., 2001), modeling of rainfall-runoff (Liong et al., 2002) and suspended sediment modeling (Aytek and Kisi, 2008) are among researches carried out by using GP in which its priority is proved over the other methods being used. Whigham and Crapper (2001) described the application of a grammatically based genetic programming system to discover rainfall-runoff relationships for two vastly different catchments. The favorable results of the genetic programming approach showed that machine learning techniques were potentially a useful tool for developing

Corresponding Author: Mohammad Ali Ghorbani, Department of Water Engineering, Faculty of Civil Engineering, Tabriz University, Tabriz, Iran 
hydrological models, especially when surface water movement and water losses were poorly understood. Ghorbani et al. (2010) used GP to forecast sea level variations, 3 time steps ahead for a set of time intervals using observed sea levels in Hillarys Boat Harbor, Australia.

They compared the results with a corresponding set of published results using an Artificial Neural Network Model. The results showed that both these artificial intelligence methodologies performed satisfactorily and might be considered as alternatives to the harmonic analysis. Arganis et al. (2009) presentesan application of genetic programming without and with standardization data with the aim of modeling the behavior of the water temperature in Ebro river in terms of meteorological variables that are easily measured in attempts to explain the possible evolution of the water temperature behavior.

According to the results, it was feasible to obtain some improvements in generating water temperature models by means of genetic programming when the standardization process was incorporated. Results also showed limits on the developed models. Nasseri et al. (2011) developed a hybrid model which combined Extended Kalman Filter (EKF) and Genetic Programming (GP) for forecasting of water demand in Tehran, Iran. Results of GP and hybrid models of EKFGP demonstrated the visible effect of observation precision on water demand prediction.

They addressed that the results could help decision makers of water resources to reduce their risks of online water demand forecasting and optimal operation of urban water systems. So far, a number of researches in agro hydrological fields have been carried out by using Adaptive Neuro Fuzzy Inference System. Nayak et al. (2004, 2005) used ANFIS Models for short-term streamflow and flood forecasting. Kisi (2006) investigated the accuracy of ANFIS Technique in daily evaporation modeling. Kisi and Ozturk (2007) used this technique for the estimation of the evapotranspiration to predict the water need rate of the reference crop.

The goal of the research presented herein was to develop three intelligent models including the ANNs, GP and ANFIS for maximum, minimum and mean air temperature estimation in the synoptic station of Tabriz city which is one of the important meteorological stations in Iran.

Previous studies have used different ANN Methods for the estimation of minimum, mean or maximum air temperature. The novelty of the present study was to evaluate the capabilities of ANFIS and GP Models as tools for estimating air temperature.

\section{MATERIALS AND METHODS}

Artificial Neural Networks: ANNs are parallel information processing system. A neural network consists of a set of neurons or nodes arranged in layers and in the case that weighted inputs are used, these nodes provide suitable inputs by conversion functions. Any layer consists of pre-designated neurons and each neural network includes one or more of these interconnected layers.

The operation process of these networks is so that the input layer accepts the data and the intermediate layer processes them and finally, the output layer displays the resultant outputs of the model application. During the modeling stage, the coefficients related to the present errors in the nodes are corrected through comparing the model outputs with the recorded input data. Further information on ANNs can be found by Haykin (1998).

Multi-layer Perceptrons (MLP) are feedforward networks with one or more hidden layers. The neural network employed in this study possessed a three-layer learning network consisting of an input layer, a hidden layer and an output layer as shown in Fig. 1.

Adaptive Neuro Fuzzy Inference System: An adaptive network is utilized to embed the Sugeno Fuzzy Model into its framework to facilitate the learning of the Sugeno Fuzzy Model. This can also compute the gradient vectors systematically.

This network architecture is called Adaptive Network-based Fuzzy Inference System or Adaptive Neuro-Fuzzy Inference System (ANFIS). This is a universal approximator first introduced by Jang (1993) capable of approximating any real continuous function on a compact set to any degree of accuracy. It identifies a set

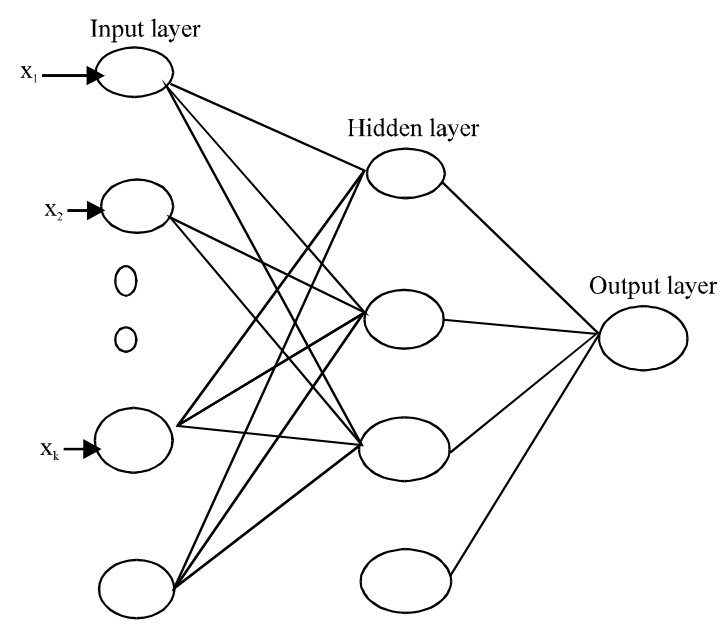

Fig. 1: The structure of the artificial neural networks 


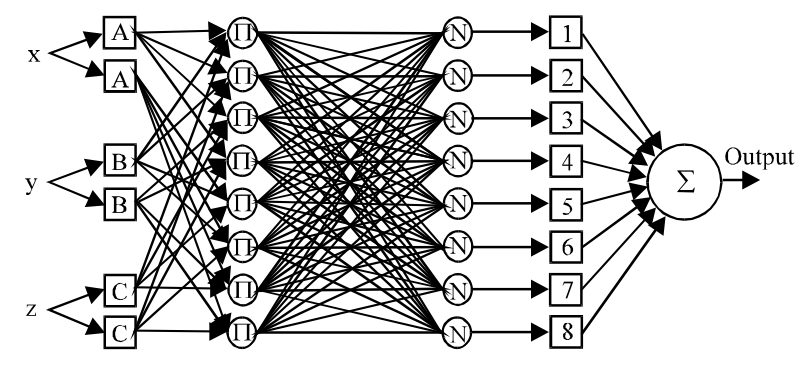

Fig. 2: A typical ANFIS architecture

of parameters through a hybrid learning rule combining the back-propagation gradient descent error digestion and a least-square method. It can be used as a basis for constructing a set of fuzzy if then rules with appropriate membership functions in order to generate the preliminary stipulated input-output pairs. Figure 2 shows a typical ANFIS architecture where Moghaddamnia et al. (2009) outline:

Layer 1: Every node in this layer is an adaptive node with a node function that may be a generalized bell membership function or a Gaussian membership function.

Layer 2: Every node in this layer is a fixed node labeled, $I$, representing the firing strength of each rule and is calculated by the fuzzy and connective of the product of the incoming signals.

Layer 3: Every node in this layer is a fixed node labeled $\mathrm{N}$, representing the normalized firing strength of each rule. The ith node calculates the ratio of the ith rule's firing strength to the sum of two rules' firing strengths.

Layer 4: Every node in this layer is an adaptive node with a node function indicating the contribution of ith rule toward the overall output.

Layer 5: The single node in this layer is a fixed node labeled $\Sigma$ indicating the overall output as the summation of all incoming signals. The above comprise three different types of components as follows (Lughofer, 2003):

- Premise parameters as non-linear parameters that appear in the input membership functions

- Consequent parameters as linear parameters that appear in the rules consequents (output weights)

- Rule structure that needs to be optimized to achieve a better linguistic interpretability
Genetic Programming (GP): The GP is similar to Genetic Algorithm (GA) but employs a parse tree structure for the search of its solutions whereas the GA employs bite strips. The technique is truly a bottom up process as there is no assumption made on the structure of the relationship between the independent and dependent variables but an appropriate relationship is identified for any given time series. The relationship can be logical statements or it is normally a mathematical expression which may be in some familiar mathematical format or it may assemble a mathematical function in a completely unfamiliar format. The construction of the relationship is made possible by two components: a parse tree which is a functional set of basic operators and those selected in this study are:

$$
\{+,-, \times\}\{+,-, \times, x\}
$$

which emulates the role of RNA and the actual components of the functions and their parameters (referred to as the terminal set) which emulates the role of RNA. When these two components work hand-in-hand, only then efficient emulation of evolutionary processes become possible.

The relationship between the independent and dependent variables are often referred to as the model, the program or the solution but whatever the terminology, the identified relationship in a particular GP modeling is continually evolving and never fixed. As the population evolves from one generation to another, new models replace the old ones by having demonstrably better performance. The evolution starts from an initially selected random population of models where the fitness value of each model is evaluated using the values of the independent and dependent variables. There are various selection methods and include ranking in which individual models are ranked and selected according to their fitness values; selection by tournament in which the population is regarded as a gene pool of models and a certain number of models are picked up randomly and are then compared according to their fitness; a set number of winners are picked based on their fitness values.

Applying operators like crossover and mutation to the winners, children or offspring are produced in which crossovers are responsible for maintaining identical features from one generation to another but mutation causes a random change in the parse tree, although data mutation is also possible. This completes the operations at the initial generation and the process is repeated until the termination. There are now various software applications for implementing GP models and Fig. 3 presents a typical implementation procedure. The method used in this study is referred to as the Gene Expression 


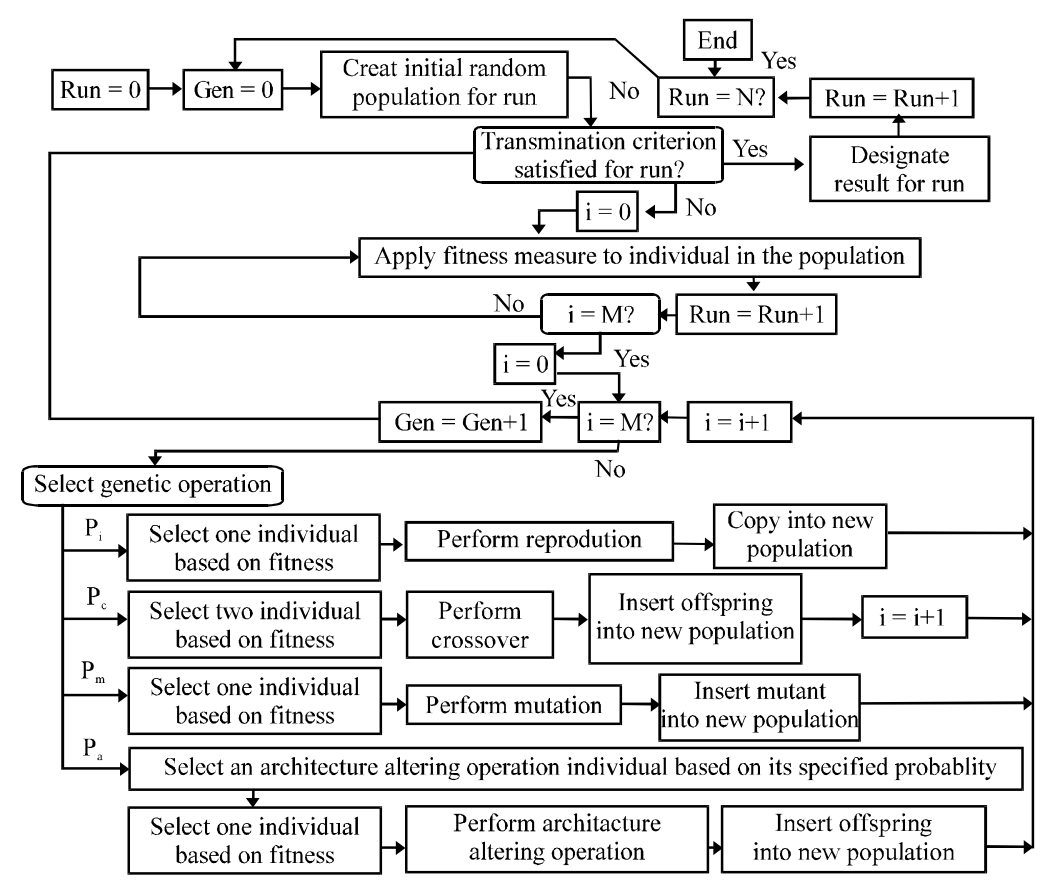

Fig. 3: Flowchart of genetic programming (Koza, www.genetic-programming.com)

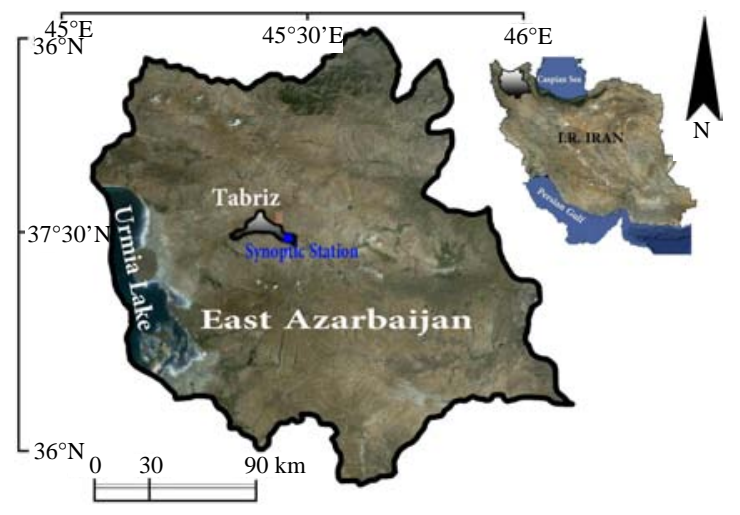

Fig. 4: The geographical location of the study area

Programming (GEP) based on evolving computer programs of different sizes and shapes encoded in linear chromosomes of fixed lengths (Ferreira, 2001).

\section{Experimental investigations}

Study are and data used: Daily air temperature data from Tabriz synoptic station is used in this study. The station is located in Iran North-West $38^{\circ} 4^{\prime} \mathrm{N}, 46^{\circ} 17^{\prime} \mathrm{E}$ with elevation of $1364 \mathrm{~m}$ above sea level. Figure 4 shows the geographical location of the study area. Table 1 shows the statistics of the applied 15 years data from 21st March, 1992 to 20th March, 2007. According to Table 1, the minimum temperature has the least value of variance and
Table 1: Some statistical parameters of the temperature $\left({ }^{\circ} \mathrm{C}\right)$ data used

\begin{tabular}{lrrr}
\hline Statistical parameters & Maximum & Minimum & \multicolumn{1}{c}{ Mean } \\
\hline Number & 5478.00 & 5478.00 & 5478.00 \\
Average $\left({ }^{\circ} \mathrm{C}\right)$ & 18.85 & 7.94 & 12.93 \\
Max. $\left({ }^{\circ} \mathrm{C}\right)$ & 40.60 & 28.00 & 23.20 \\
Min. $\left({ }^{\circ} \mathrm{C}\right)$ & -8.40 & -19.50 & -15.00 \\
Variance $\left({ }^{\circ} \mathrm{C}^{2}\right)$ & 125.65 & 84.68 & 104.89 \\
Skewness $\left({ }^{\circ} \mathrm{C}^{2}\right)$ & -0.13 & -0.11 & -0.10 \\
SD $\left({ }^{\circ} \mathrm{C}\right)$ & 11.21 & 9.20 & 10.24 \\
\hline
\end{tabular}

the maximum value of variance is for the maximum temperature. Also, the values of skewness and standard deviation are higher for the maximum temperature than those of the minimum and mean temperature.

Evaluation criteria: In addition to the scatter plots and observed and simulated comparative diagrams, determination of coefficient $\left(\mathrm{R}^{2}\right)$ and Root Mean Squared Error (RMSE) and the Coefficient of Efficiency (CE) (Nash and Sutcliffe, 1970) were used to evaluate the models' performance, expressions for which are presented as:

$$
\begin{gathered}
R^{2}=\left(\frac{\sum_{i=1}^{\mathrm{N}}\left(\mathrm{T}_{\mathrm{i}}^{0}-\overline{\mathrm{T}}^{0}\right)\left(\mathrm{T}_{i}^{\mathrm{E}}-\overline{\mathrm{T}}^{\mathrm{E}}\right)}{\sqrt{\sum_{\mathrm{i}=1}^{\mathrm{N}}\left(\mathrm{T}_{\mathrm{i}}^{\mathrm{o}}-\overline{\mathrm{T}}^{0}\right)^{2} \sum_{i=1}^{\mathrm{N}}\left(\mathrm{T}_{\mathrm{i}}^{\mathrm{E}}-\overline{\mathrm{T}}^{\mathrm{E}}\right)^{2}}}\right)^{2} \\
\operatorname{RMSE}=\sqrt{\frac{\sum_{\mathrm{i}=1}^{\mathrm{N}}\left(\mathrm{T}_{\mathrm{i}}^{\mathrm{E}}-\mathrm{T}_{\mathrm{i}}^{\mathrm{o}}\right)^{2}}{\mathrm{~N}}}
\end{gathered}
$$




$$
\mathrm{CE}=1-\left[\frac{\sum_{\mathrm{i}=1}^{\mathrm{N}}\left(\mathrm{T}_{\mathrm{i}}^{\mathrm{o}}-\mathrm{T}_{\mathrm{i}}^{\mathrm{E}}\right)}{\sum_{\mathrm{i}=1}^{\mathrm{N}}\left(\mathrm{T}_{\mathrm{i}}^{\mathrm{o}}-\overline{\mathrm{T}}^{\mathrm{o}}\right)}\right]
$$

Where:

$$
\begin{array}{ll}
\mathrm{T}_{\mathrm{i}}{ }^{\circ} & =\text { The value observed at the ith time step } \\
\mathrm{T}_{\mathrm{i}}{ }^{\mathrm{e}} & =\text { The corresponding estimated value } \\
\overline{\mathrm{T}}^{\mathrm{O}} \text { and } \overline{\mathrm{T}}^{\mathrm{E}}= & \text { The mean values of the observed and the } \\
& \text { estimated air temperature, respectively } \\
\mathrm{N} & =\text { The number of data }
\end{array}
$$

\section{RESULTS AND DISCUSSION}

Data applied in this study include the minimum, maximum and mean air temperature values of Tabriz synoptic station recorded over a statistical period of 15 years from March 21st, 1992 to March 20th, 2007. These data were entered into models in various combinations by the allocation of about 10 years to the training period and about 5 years to the test period. In order to examine the accuracy of each mentioned method, various combinations of the air temperature values were formed up to 3 days ago and then were used as the inputs of these models. The initial parameters for the GP, ANN and ANFIS Model runs are shown in Table 2.

Training period: Table 3 shows the values related to each statistical index of different air temperature models in the training period. As mentioned before, the determination coefficient $\left(\mathrm{R}^{2}\right)$, Root Mean Squared Error (RMSE) and the Coefficient of Efficiency (CE) (Nash and Sutcliffe, 1970) were used to evaluate the models. Examining these indices for different models and combinations, it is considered that in every three models, the third combination is the best one. In other words, the increase of the air temperature values of different time steps as input parameters results in the change and relative improvement of these models. It can generally be said that all three models have acceptable close answers and can be used for the test period.

Test period: Table 4 shows the statistical analysis of ANFIS, ANN and GP Models for the test period.

\begin{tabular}{|c|c|c|c|c|c|c|c|c|c|c|}
\hline \multirow[b]{2}{*}{ Models } & & \multicolumn{3}{|l|}{$\mathrm{T}_{\max }$} & \multicolumn{3}{|l|}{$\mathrm{T}_{\min }$} & \multicolumn{3}{|l|}{$\mathrm{T}_{\text {mean }}$} \\
\hline & & $\mathrm{R}^{2}$ & RMSE & $\mathrm{CE}$ & $\mathrm{R}^{2}$ & RMSE & $\mathrm{CE}$ & $\mathrm{R}^{2}$ & RMSE & $\mathrm{CE}$ \\
\hline \multirow[t]{3}{*}{ GP } & $\mathrm{T}_{\mathrm{i}-1}$ & 0.950 & 2.462 & 0.950 & 0.935 & 2.307 & 0.935 & 0.965 & 1.874 & 0.965 \\
\hline & $\mathrm{T}_{\mathrm{i}-1,1}, \mathrm{~T}_{\mathrm{i}-2}$ & 0.950 & 2.463 & 0.950 & 0.935 & 2.300 & 0.935 & 0.966 & 1.842 & 0.966 \\
\hline & $\mathrm{T}_{\mathrm{i}-1}, \mathrm{~T}_{\mathrm{i}-2}, \mathrm{~T}_{\mathrm{i}-3}$ & 0.951 & 2.447 & 0.951 & 0.937 & 2.276 & 0.936 & 0.966 & 1.846 & 0.966 \\
\hline \multirow[t]{3}{*}{ ANN } & $\mathrm{T}_{\mathrm{i}-1}$ & 0.951 & 2.449 & 0.951 & 0.936 & 2.290 & 0.938 & 0.965 & 1.867 & 0.965 \\
\hline & $\mathrm{T}_{\mathrm{i}-1}, \mathrm{~T}_{\mathrm{i}-2}$ & 0.951 & 2.446 & 0.951 & 0.937 & 2.263 & 0.937 & 0.966 & 1.973 & 0.961 \\
\hline & $\mathrm{T}_{\mathrm{i}-1}, \mathrm{~T}_{\mathrm{i}-2}, \mathrm{~T}_{\mathrm{i}-3}$ & 0.952 & 2.426 & 0.952 & 0.938 & 2.243 & 0.938 & 0.967 & 2.024 & 0.959 \\
\hline \multirow[t]{3}{*}{ ANFIS } & $\mathrm{T}_{\mathrm{i}-1}$ & 0.948 & 2.515 & 0.948 & 0.931 & 2.376 & 0.931 & 0.963 & 1.933 & 0.965 \\
\hline & $\mathrm{T}_{\mathrm{i}-1}, \mathrm{~T}_{\mathrm{i}-2}$ & 0.950 & 2.445 & 0.950 & 0.936 & 2.277 & 0.936 & 0.966 & 1.861 & 0.968 \\
\hline & $\mathrm{T}_{\mathrm{i} 1,}, \mathrm{~T}_{\mathrm{i} 2}, \mathrm{~T}_{\mathrm{i} 3}$ & 0.953 & 2.395 & 0.953 & 0.939 & 2.232 & 0.939 & 0.969 & 1.773 & 0.969 \\
\hline
\end{tabular}

Selection of the best models: Averaging out the $\mathrm{R}^{2}$ and RMSE values of three patterns considered for each model,

\begin{tabular}{|c|c|c|c|c|c|c|c|c|c|c|}
\hline \multirow[b]{2}{*}{ Models } & & \multicolumn{3}{|l|}{$\mathrm{T}_{\max }$} & \multicolumn{3}{|l|}{$\mathrm{T}_{\text {min }}$} & \multicolumn{3}{|l|}{$\mathrm{T}_{\text {mean }}$} \\
\hline & & $\mathrm{R}^{2}$ & RMSE & $\mathrm{CE}$ & $\mathrm{R}^{2}$ & RMSE & $\mathrm{CE}$ & $\mathrm{R}^{2}$ & RMSE & $\mathrm{CE}$ \\
\hline \multirow[t]{4}{*}{ GP } & $T_{i-1}$ & 0.951 & 2.569 & 0.951 & 0.929 & 2.561 & 0.929 & 0.967 & 1.951 & 0.967 \\
\hline & $\mathrm{T}_{\mathrm{i}-1}, \mathrm{~T}_{\mathrm{i} \cdot 2}$ & 0.951 & 2.567 & 0.951 & 0.929 & 2.573 & 0.928 & 0.968 & 1.905 & 0.968 \\
\hline & $\mathrm{T}_{\mathrm{i}-1}, \mathrm{~T}_{\mathrm{i}-2}, \mathrm{~T}_{\mathrm{i}-3}$ & 0.952 & 2.566 & 0.951 & 0.930 & 2.536 & 0.930 & 0.968 & 1.927 & 0.967 \\
\hline & Average & 0.951 & 2.567 & 0.951 & 0.929 & 2.557 & 0.929 & 0.968 & 1.928 & 0.967 \\
\hline \multirow[t]{4}{*}{ ANN } & $\mathrm{T}_{\mathrm{i}-1}$ & 0.951 & 2.563 & 0.951 & 0.930 & 2.547 & 0.929 & 0.967 & 1.945 & 0.967 \\
\hline & $\mathrm{T}_{\mathrm{i}-1}, \mathrm{~T}_{\mathrm{i}-2}$ & 0.951 & 2.562 & 0.951 & 0.931 & 2.517 & 0.931 & 0.968 & 2.011 & 0.965 \\
\hline & $T_{i-1}, T_{i-2}, T_{i-3}$ & 0.952 & 2.547 & 0.952 & 0.932 & 2.492 & 0.932 & 0.970 & 2.056 & 0.963 \\
\hline & Average & 0.951 & 2.557 & 0.951 & 0.931 & 2.519 & 0.931 & 0.968 & 2.004 & 0.965 \\
\hline \multirow[t]{4}{*}{ ANFIS } & $\mathrm{T}_{\mathrm{i}-1}$ & 0.950 & 2.603 & 0.950 & 0.927 & 2.592 & 0.927 & 0.965 & 2.010 & 0.966 \\
\hline & $\mathrm{T}_{\mathrm{i}-1}, \mathrm{~T}_{\mathrm{i}-2}$ & 0.951 & 2.560 & 0.951 & 0.931 & 2.510 & 0.931 & 0.968 & 1.928 & 0.967 \\
\hline & $\mathrm{T}_{\mathrm{i}-1}, \mathrm{~T}_{\mathrm{i}-2}, \mathrm{~T}_{\mathrm{i}-3}$ & 0.952 & 2.540 & 0.952 & 0.931 & 2.523 & 0.931 & 0.969 & 1.883 & 0.969 \\
\hline & Average & 0.951 & 2.568 & 0.951 & 0.930 & 2.542 & 0.930 & 0.967 & 1.940 & 0.977 \\
\hline
\end{tabular}

Table 2: GP, ANN and ANFIS parameters settings

\begin{tabular}{lll}
\hline Models & Parameters & Value/type \\
\hline GP & Mutation & 0.044 \\
& Inversion & 0.1 \\
& No. of chromosomes & 30 \\
& Head size & 7 \\
& No. of genes & 3 \\
ANN & Iteration number & 10000 \\
& Activation functions & Sigmoid \\
& Hidden layer neurons & 4 \\
\multirow{2}{*}{ ANFIS } & Training algorithm & Levenberg-Marquardt \\
& Type of membership function & Gaussian \\
& No. of membership function & 4 \\
\hline
\end{tabular}

Table 3: Statistical analysis of the estimated values for the training period

Table 4: Statistical analysis of the estimated values for the test period 
it is seen that ANN, ANN and GP perform better for the estimation of maximum, minimum and mean air temperature, respectively. In terms of $\mathrm{R}^{2}$, RMSE and $\mathrm{CE}$, ANFIS, ANN and GP perform better for the estimation of mean temperature.

The mean air temperature forecasts of these three models seem to be better than those for the maximum and minimum air temperatures. The reason behind this may be the fact that the variance, skewness and standard deviation statistics are lower for the mean air temperature than those of the minimum and maximum air temperatures.

Selection of the best patterns: For maximum temperature, GP, ANN and ANFIS (RMSE, $\mathrm{R}^{2}$ and CE) performs better with the third pattern. Therefore, the third pattern has better results for maximum temperature estimation. For minimum temperature, GP and ANN ( ${ }^{2}, \mathrm{RMSE}$ and $\mathrm{CE}$ ) perform better with the third pattern. ANFIS (RMSE) performs better with the second pattern and ANFIS ( $\mathrm{R}^{2}$ and $\mathrm{CE}$ ) with both second and third patterns. It can be concluded that the third pattern has better results for minimum temperature estimation.

For mean temperature however, it is difficult to find the best pattern. ANN and ANFIS $\left(\mathrm{R}^{2}\right)$ perform better with the third pattern and GP $\left(\mathrm{R}^{2}\right)$ with both second and third patterns. GP (CE) performs better with the third pattern, ANN (CE) performs better with the first pattern and ANFIS (RMSE) performs better with the third pattern while ANN (RMSE) performs better with the first pattern. Figure 5-13 show the best observed versus simulated plots along with the distribution diagrams for the minimum, maximum and mean temperatures, respectively.
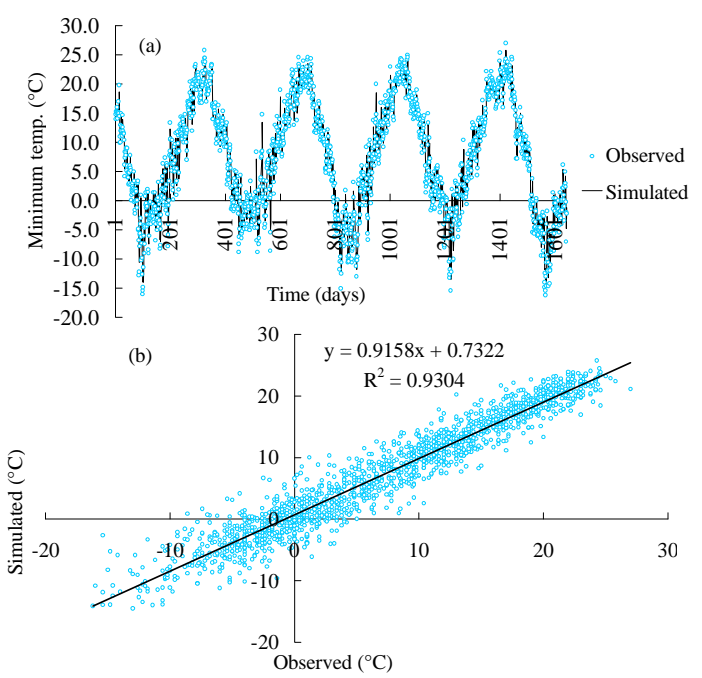

Fig. 5: Results of GP for minimum temperature: a) Time-series plot; b) Scatter plot
In forecasting minimum air temperature case (Fig. 5-7) from the fit line equations (assume that the equation is $y=a_{0} x+a_{1}$ ) in the scatterplots where the $a_{0}$ coefficient for the ANN Model is closer to 1 with a higher $\mathrm{R}^{2}$ value than those of GP and ANFIS models. This is also confirmed by the RMSE and $\mathrm{R}^{2}$ values in Table 3 . For forecasting maximum and mean air temperature cases (Fig. 8-13), however, it is difficult to say which model is better than the other. According to Table 3 and the mentioned Fig. 5-13, it is well understood that all three models are of acceptable accuracy and therefore can be used for the air temperature forecasting. Meanwhile, models based on genetic programming have relative priority compared to the other models since they present
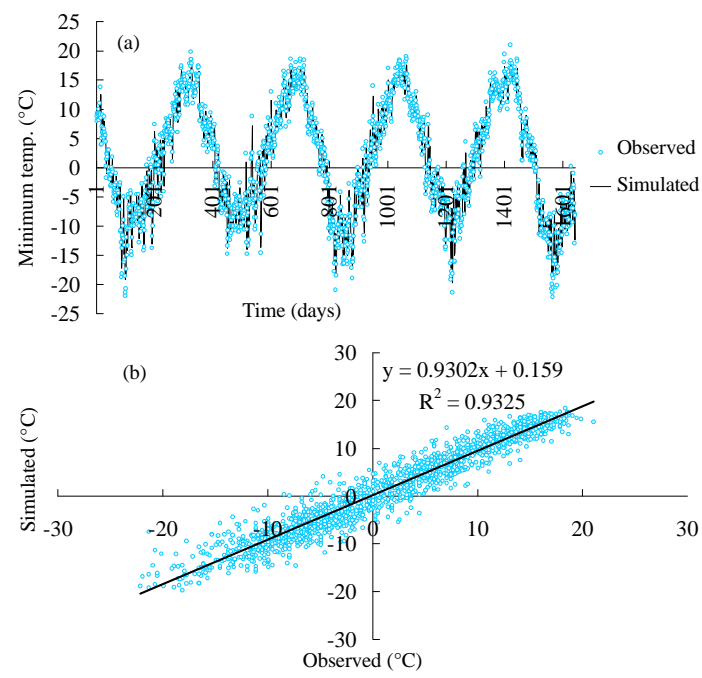

Fig. 6: Results of ANN for minimum temperature; a) Time-series plot and b) Scatter plot
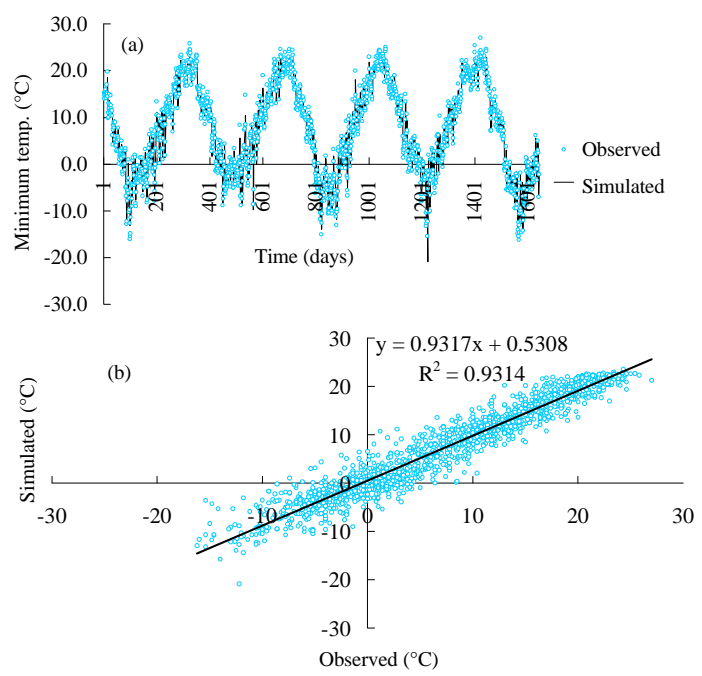

Fig. 7: Results of ANFIS for minimum temperature: a) Time-series plot; b) Scatter plot 

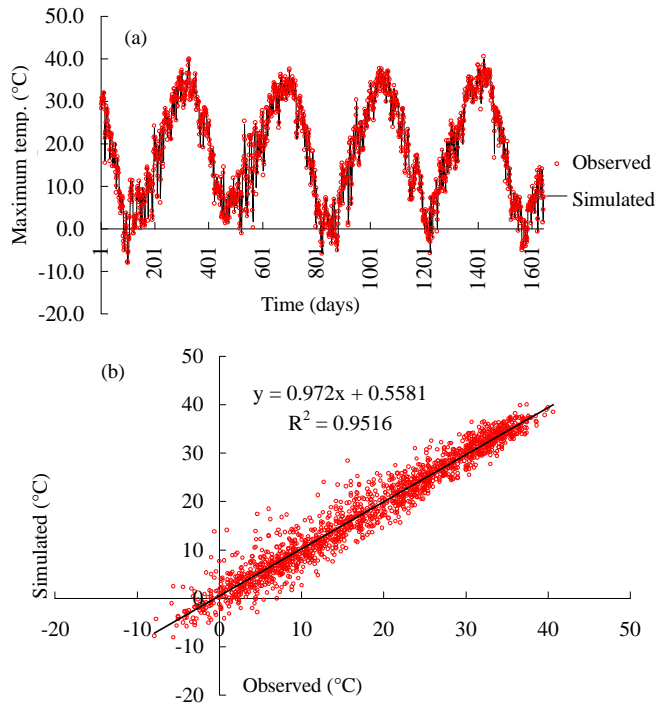

Fig. 8: Results of GP for maximum temperature: a) Time-series plot; b) Scatter plot
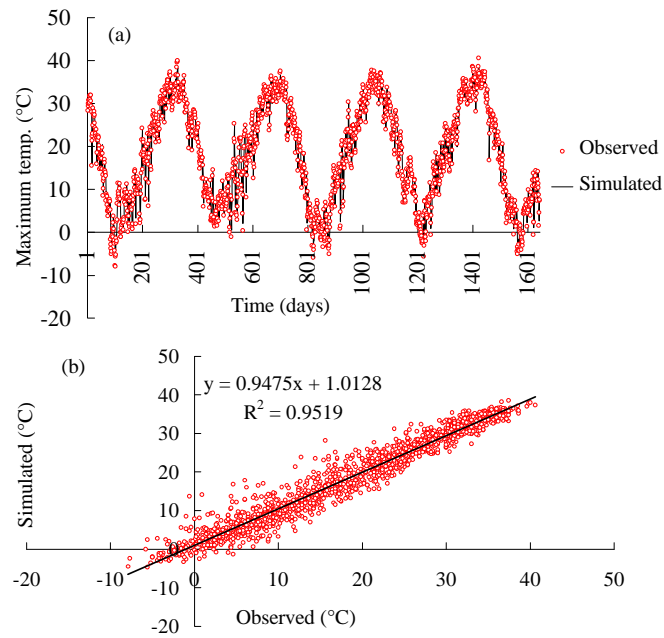

Fig. 9: Results of ANN for maximum temperature: a) Time-series plot; b) Scatter plot

an explicit solution between input and output variables. In other words, genetic programming is able to present the existing approximate equation between inputs and outputs of the model. This property distinguishes it from the other models such as neural networks and Neuro Fuzzy Systems. As it is shown in Table 3, GP performs better when the third pattern is used for the simulations except for the mean temperature in which the second pattern i.e., when the data of two days ago are entered as the model input. The equations presented by GP for the estimation of minimum, mean and maximum air temperature for the best mentioned patterns are as follows:
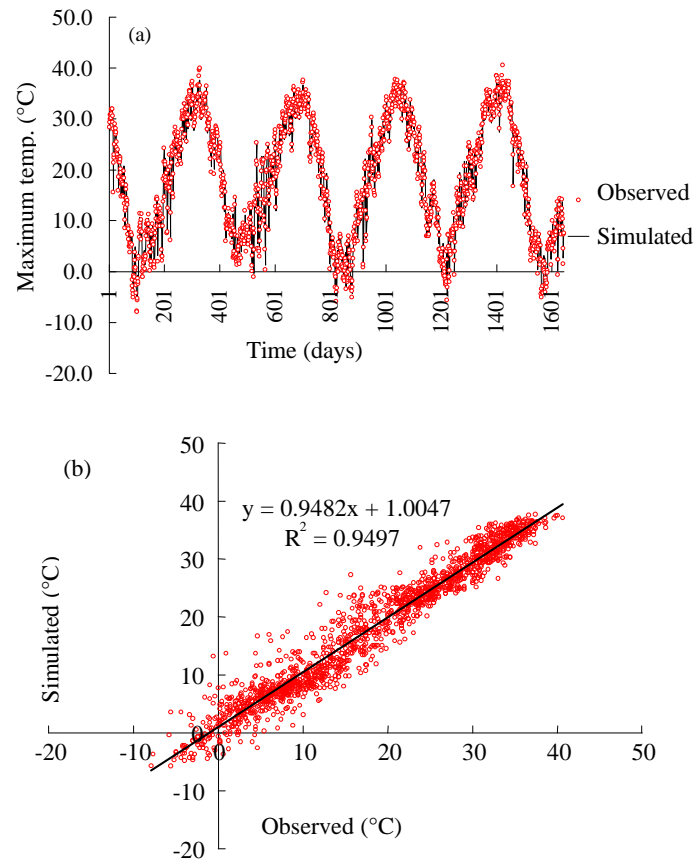

Fig. 10: Results of ANFIS for maximum temperature: a) Time-series plot; b) Scatter plot
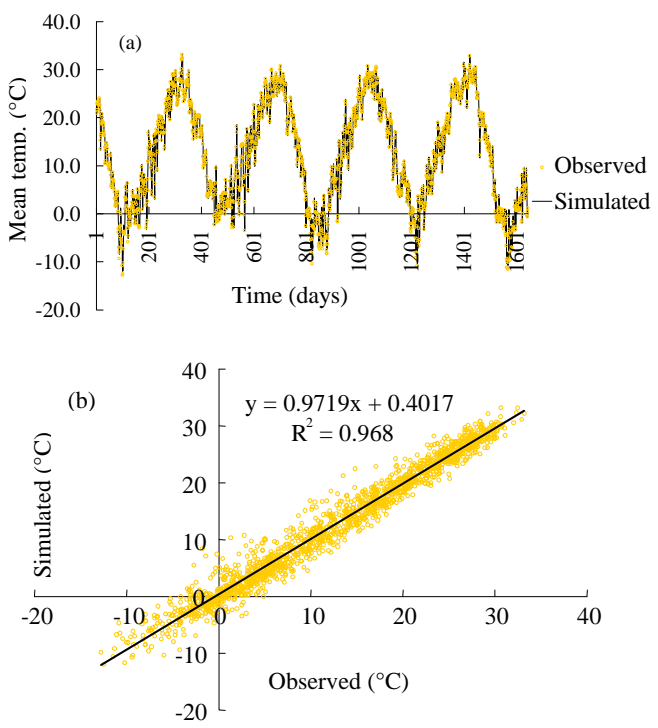

Fig. 11: Results of GP for mean temperature: a) Time-series plot; b) Scatter plot

$$
\begin{aligned}
& \mathrm{T}_{\mathrm{i}_{\max }}=\mathrm{T}_{\mathrm{i}-1_{\max }}+0.009 \mathrm{~T}_{\mathrm{i}-\mathrm{g}_{\max }} *\left(\mathrm{~T}_{\mathrm{i}-\mathrm{s}_{\max }}-\mathrm{T}_{\mathrm{i}-\mathrm{z}_{\max }}\right) \\
& \mathrm{T}_{\mathrm{i}_{\text {min }}}=0.958 \mathrm{~T}_{\mathrm{i}^{3} 3_{\text {min }}}+0.402 \\
& \mathrm{~T}_{\mathrm{i}_{\text {max }}}=-0.025 \mathrm{~T}_{\mathrm{i}-\mathrm{I}_{\text {man }}}+\mathrm{T}_{\mathrm{i}-2_{\text {max }}}+0.333
\end{aligned}
$$



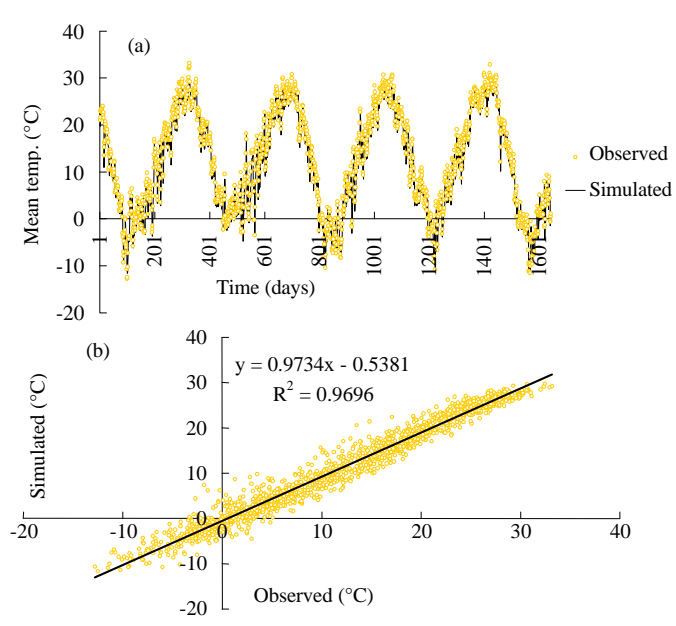

Fig. 12: Results of ANN for mean temperature: a) Time-series plot; b) Scatter plot
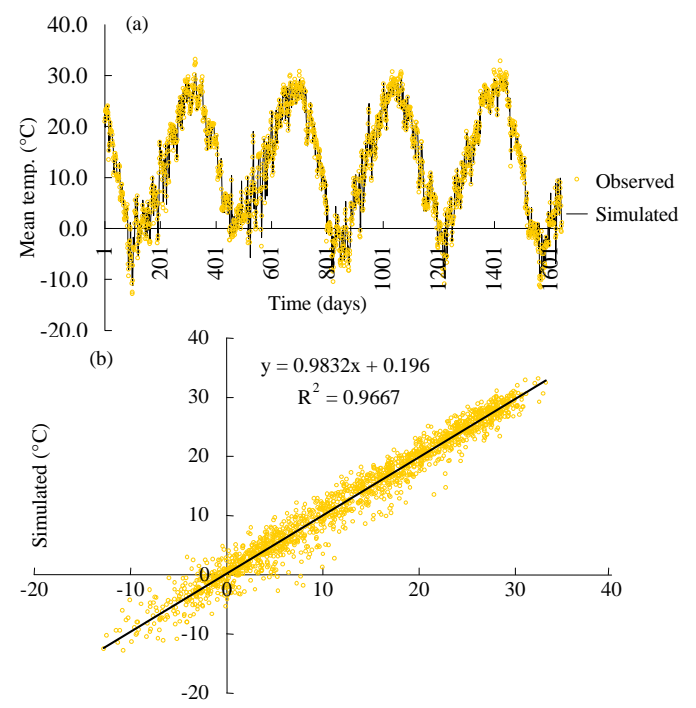

Fig. 13: Results of ANFIS for mean temperature: a) Time-series plot and b) Scatter plot

\section{CONCLUSION}

Modeling and estimation of air temperature is of important and considerable factors in agricultural meteorology also in scheduling, design and management of water resources. Sometimes, maximum andminimum air temperature approaches critical values which is a limitation for agricultural crops and brings about potential losses due to extreme cold and heat. This makes it necessary to have accurate and robust models to model the air temperature variations. In the present research, artificial neural networks, Adaptive Neuro Fuzzy Inference System and genetic programming are used for the estimation of maximum, minimum and mean air temperature values. On the basis of the calculations carried out, all three models can reliably be applied to estimate the air temperature. The models based on genetic programming present explicit solutions on the basis of which the relation between the input and output variables can be specified. This can be suggested as a subject for further researches. The overall result is that intelligent methods can be applied to model the meteorological parameters such as the air temperature with an acceptable accuracy. This is confirmed by the results of Ustaoglu et al. (2008) research for the modeling of the daily maximum, minimum and mean temperatures using artificial neural networks.

\section{ACKNOWLEDGEMENT}

The researchers are grateful to Tabriz Meteorological Center for making available the daily air temperature observations.

\section{REFERENCES}

Abde-Al, M.A. and M.E. El-Hadidi, 1994. A machine learning approach to modeling and forecasting the minimum temperature at Haahran. Saudi Arabia Energy, 19: 739-749.

Arganis, M., R. Val, J. Prats, K. Rodriguez, R. Dominguez and J. Dolz, 2009. Genetic programming and standardization in water temperature modeling. Adv. Civil Eng., Vol. 2009, 10.1155/2009/353960

Aytek, A. and O. Kisi, 2008. A genetic programming approach to suspended sediment modelling. J. Hydrol., 351: 288-298.

Brunt, D., 1941. Physical and Dynamic Meteorology. 2nd Edn., Cambridge University Press, New York.

Dombayci, O.A. and M. Golcu, 2009. Daily means ambient temperature prediction using artificial neural network method: A case study of Turkey. Renewable Energy, 34: 1158-1161.

Elizondo, D.A., R.W. McClendon and G. Hoogenboom, 1994. Neural network models for predicting flowering and physiological maturity of soybean. Trans. ASAE., 37: 981-988.

Ferreira, C., 2001. Gene expression programming: A new adaptive algorithm for solving problems. Complex Syst., 13: 87-129.

Ghorbani, M.A., R. Khatibi, A. Aytek, O. Makarynskyy and J. Shiri, 2010. Sea water level forecasting using genetic programming and comparing the performance with artificial neural networks. Comput. Geosci., 36: 620-627. 
Haykin, S., 1998. Neural Networks: A Comprehensive Foundation. Prentice-Hall, Upper Saddle River, New Jersey, Pages: 842.

Jang, J.S.R., 1993. ANFIS: Adaptive-network-based fuzzy inference system. IEEE Trans. Syst. Manage. Cybernet., 23: 665-685.

Khu, S.T., S.Y. Liong, V. Babovic, H. Madsen and N. Muttil, 2001. Genetic programming and its application in real-time runoff forecasting. J. Am. Water Resour. Assoc., 37: 439-451.

Kisi, O. and O. Ozturk, 2007. Adaptive neurofuzzy computing technique for evapotranspiration estimation. J. Irrig. Drain Eng., 133: 368-379.

Kisi, O., 2006. Daily pan evaporation modelling using a neuro-fuzzy computing technique. J. Hydrol., 329: 636-646.

Liong, S.Y., T.R. Gautam, S.T. Khu, V. Babovic, M. Keijzer and N. Muttil, 2002. Genetic programming: A new paradigm in rainfall runoff modeling. J. Am. Water Resourc. Assoc., 38: 705-718.

Lughofer, E., 2003. Online adaptation of Takagi-Sugeno fuzzy inference systems. Technical Report, Fuzzy Logic Laboratorium, Linz-Hagenberg.

Moghaddamnia, A., M.G. Gousheh, J. Piri, S. Amin and D. Han, 2009. Evaporation estimation using artificial neural networks and adaptive neurofuzzy inference system techniques. Adv. Water Resourc., 32: 88-97.

Nash, J.E. and J.V. Sutcliffe, 1970. River flow forecasting through conceptual models I: A discussion of principles. J. Hydrol., 10: 282-290.

Nasseri, M., A. Moeini and M. Tabesh, 2011. Forecasting monthly urban water demand using extended kalman filter and genetic programming. Exp. Syst. Appl., 38: 7387-7395.
Nayak, P.C., K.P. Sudheer, D.M. Rangan and K.S. Ramasastri, 2004. A neuro-fuzzy computing technique for modeling hydrological time series. J. Hydrol., 291: 52-66.

Nayak, P.C., K.P. Sudheer, D.M. Rangan and K.S. Ramasastri, 2005. Short-term flood forecasting with a neurofuzzy model. Water Resourc. Res., Vol. 41, 10.1029/2004WR003562.

Panigrahi, S. and L.J. Francl, 1997. Artificial neural network models of wheat leaf wetness. Agric. Forest Meteorol., 88: 57-65.

Paruelo, J.M. and F. Tomasel, 1997. Prediction of functional characteristics of ecosystems: A comparison of artificial neural networks and regression models. Ecol. Modell., 98: 173-186.

Patterson, D.W., 1996. Artificial Neural Networks: Theory and Applications. Prentice Hall, Singapore, Pages: 477.

Robinson, C. and N. Mort, 1997. A neural network system for the protection of citrus crops from frost damage. Comput. Electron. Agric., 16: 177-187.

Smith, B.A., G. Hoogenboom and R.W. McClendon, 2009. Artificial neural networks for automated year-round temperature prediction. Comput. Electron. Agric., 68: 52-61.

Ustaoglu, B., H.K. Cigizoglu and M. Karaca, 2008. Forecast of daily mean, maximum and minimum temperature time series by three artificial neural network methods. Meteorol. Appl., 15: 431-445.

Whigham, P.A. and P.F. Crapper, 2001. Modelling rainfallrunoff using genetic programming. Math. Comput. Modell., 33: 707-721. 